\title{
Influence of biophysical properties on temporal filters in a sensory neuron
}

\author{
Jan-Hendrik Schleimer ${ }^{1 *}$, Susanne Schreiber ${ }^{2}$ \\ From Twenty Second Annual Computational Neuroscience Meeting: CNS*2013 \\ Paris, France. 13-18 July 2013
}

Sensory pathways implement filters that extract relevant information from the environment [1]. These filtering properties depend in intricate ways on the biophysical parameters of the underlying neuronal architecture. Understanding the link between computational aspects, such as response properties or spike statistics, and the underlying biophysics is a question that can be addressed with theoretical methods.

Many primary sensory neurons operate in a mean-driven regime, where mean intensity is represented by the average firing rate, while the temporal structure of the stimulus around its mean is encoded into the particular structure of the spike train in analogy to an irregular sampler [2]. Examples of neurons applying this strategy include the paddlefish's electrosensory system [3], grasshopper auditory receptors [4], or the vestibular system of the turtle [5].

Spikes are generated from the dynamics of voltagedependent ion channels. Different sensory neurons, however, may use different compositions of spike-generating channel types. These do not only render the cell excitable in the first place, they also have a large influence on a neuron's transfer function. In addition, some ion channels shape the subthreshold dynamics of neurons, but it is less clear, how they affect the temporal structure of spike trains when the neurons are driven tonically.

Several channel types, including HCN channels, are known to cause subthreshold resonance. This property results in largest subthreshold response amplitudes of a neuron at a particular frequency, hence termed the resonance frequency. The resulting band-pass like filter properties have a strong effect on fluctuation-driven neurons. Their influence on tonic spiking, however, has

\footnotetext{
* Correspondence: schleimj@hu-berlin.de

1 Bernstein Center for Computational Neuroscience, Berlin, Germany

Full list of author information is available at the end of the article
}

been less explored. Accordingly, the influence of channels that cause subthreshold resonance, such as $\mathrm{HCN}$, on sensory systems like the hair cells of the mouse inner ear is still under debate [6]. Here, we use phaseresponse-curve-based methods within the framework of numerical continuation to resolve whether and how the effects of these channels carry over into the suprathreshold, mean-driven dynamics.

To this end, we use computational models of hair-cell mechanoreceptors [7]. Our approach is to, first, derive the phase oscillator that is input-output equivalent to the full biophysical model. Then, applying linear response theory, the transfer function can be estimated in the regime of weak-amplitude stimulation [8]. This transfer function maps time-dependent stimuli to the instantaneous firing rate. We show that the poles and zeros of the transfer spectrum are related to the Fourier components of the systems phase response curve (PRC) as well as the average intrinsic noise level, which is due to a finite ensemble of stochastic ion channels.

We find that both properties (1) the PRC - a consequence of the deterministic part of the dynamical system and (2) the intrinsic stochasticity, are affected by the presence of HCN channels. Further, we use an overall measure of information transmission, the stimulus-response information, to approximate the contribution of $\mathrm{HCN}$ channels to information transfer in given frequency bands.

\footnotetext{
Author details

${ }^{1}$ Bernstein Center for Computational Neuroscience, Berlin, Germany. ${ }^{2}$ Institute for Theoretical Biology, Humboldt University, Berlin, Germany.

Published: 8 July 2013
References
1. Dimitrov AG, Lazar AA, Victor JD: Information theory in neuroscience. J Comput Neurosci 2011, 30:1-5.
2. Lazar AA: Information Representation with an Ensemble of Hodgkin- Huxley Neurons. Neurocomputing 2007, 70:1764-1771.


3. Neiman A, Russell D: Sensory coding in oscillatory electroreceptors of paddlefish. Chaos 2011, 21(4):047505.

4. Machens CK, Stemmler MB, Prinz P, Krahe R, Ronacher B, Herz AVM: Representation of acoustic communication signals in insect auditory receptors. J Neurosci 2001, 21:3215.

5. Rowe MH, Neiman AB: Information analysis of posterior canal afferents in the turtle Trachemys scripta elegans. Brain Research 2012, 1434:226-242.

6. Horwitz GC, Lelli A, Géléoc GSG, Holt JR: HCN Channels Are Not Required for Mechanotransduction in Sensory Hair Cells of the Mouse Inner Ear. PLOS ONE 2010, 5:e8627.

7. Neiman AB, Dierkes K, Lindner B, Han L, Shilnikov AL: Spontaneous voltage oscillations and response dynamics of a Hodgkin-Huxley type model of sensory hair cells. J Math Neurosci 2011, 1:11.

8. Schleimer $\mathrm{JH}$, Stemmler M: Coding of information in limit cycle oscillators. Phys Rev Lett 2009, 103(24):248105.

doi:10.1186/1471-2202-14-S1-P347

Cite this article as: Schleimer and Schreiber: Influence of biophysical properties on temporal filters in a sensory neuron. BMC Neuroscience 2013 14(Suppl 1):P347.

\section{Submit your next manuscript to BioMed Central} and take full advantage of:

- Convenient online submission

- Thorough peer review

- No space constraints or color figure charges

- Immediate publication on acceptance

- Inclusion in PubMed, CAS, Scopus and Google Scholar

- Research which is freely available for redistribution

Submit your manuscript at www.biomedcentral.com/submit 